\title{
Contribution to the Modeling of the Robust Control, of the Longitudinal and Lateral Helicopter Motion Analysis
}

\author{
Rabearivelo A. G., \\ $\mathrm{Ph} \mathrm{D}$ Student \\ University of Antananarivo in the STII,
}

\author{
Andrianaharison Y. \\ Full Professor, \\ Ecole Supérieure Polytechnique d'Antananarivo (ESPA), \\ University of Antananarivo,
}

\author{
Randriamitantsoa P. A., \\ Randriamitantsoa A. A., \\ Reziky Zafimarina S. H. Z. T \\ Full Professor, \\ Ecole Supérieure Polytechnique d'Antananarivo (ESPA), \\ University of Antananarivo.
}

\begin{abstract}
The purpose of this article is to present the state of the art which concerns the application of robust synthesis techniques of linear systems and mu-analysis of longitudinal and lateral flight of the helicopter.
\end{abstract}

Index Terms-- Helicopter, state feedback control, state representation, robust control, mu-analysis.

\section{INTRODUCTION}

The robust control of the helicopter is a type of control that aims to guarantee the performance and stability of a system during flight in the face of environmental disturbances and uncertainties of the model and a difficult task since the dynamics of the system is no linear, unstable on certain flight ranges and has a strongly coupled dynamic. Indeed, the mathematical model that models a real system is a representation that aims to best approximate, with simplifying assumptions, the system we want to control.

\section{METHODOLOGY}

In practice, the modeling is not precise enough to faithfully reflect the behavior of a system. Often designers use models with unstructured uncertainties that generally affect poorly known or intentionally neglected dynamics.

\subsection{Simulation of the synthesis and analysis model}

Robustness analysis is performed by incorporating all model uncertainties into a single transfer matrix without imposing any particular structure on it. In this study, assuming that several sources of uncertainties of different natures coexist, we adopt a system with model errors of direct additive form. Two other input signals, applied in two different places of the servo-control, are then taken into account, and the evolution of the performance of the looped system is monitored. The problem therefore arises as the search for a compromise between the objective sought and the means necessary to correct the system by using different methods of synthesis.

\subsection{Robust control in longitudinal and lateral flight of the} helicopter

The parameters of the system are marred by parametric uncertainty. Each uncertain coefficient $\tilde{p}_{i}$ is modeled as:

$$
\tilde{p}_{i}=p_{i}\left(1+\omega_{i} \delta_{i}\right),\left|\delta_{i}\right|<1
$$

Or :

$p_{i}$ :is the nominal value of the parameter considered;

$\omega_{i}$ : the corresponding weighting coefficient.

We have chosen $\omega_{i}=0,2$ for all the parameters.

By higher fractional linear transformation, we have:

$$
\tilde{p}_{i}=\left[Q_{22}+Q_{21} \Delta_{u}\left(I-Q_{11} \Delta_{u}\right)^{-1} Q_{12}\right]
$$

Is :

$$
Q_{i}=\left[\begin{array}{cc}
0 & p_{i} \\
\omega_{i} & p_{i}
\end{array}\right]
$$

A direct additive form model error is adopted for the synthesis of the corrector for this system (Figure 1). In our case, we will take as scaling function the scalar function:

$$
\begin{aligned}
& W_{u}=10^{-7} \frac{(s+10)}{10(s+500)} \\
& W_{p}=10 \frac{(s+5)}{10(5 s+1000)}
\end{aligned}
$$

To achieve the desired performance, it is necessary to satisfy the inequality $\left\|W_{u}(I+G K)^{-1}\right\|_{\infty}<1$.

Here, the weighting function is a scalar function, so the singular values of the sensitivity function $(I+G K)^{-1}$ over all frequency ranges must be obtained by the curve $\frac{1}{W_{u}}$. It means that 
$\left\|W_{u}(I+G K)^{-1}\right\|_{\infty}<1$ if and only if all frequencies:

$\sigma\left[(I+G K)^{-1}(j w)\right]<\left|\frac{1}{w_{u}(j w)}\right|$.

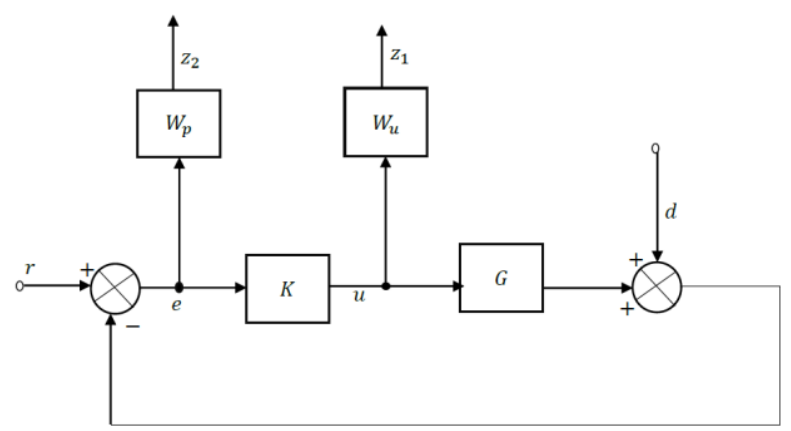

Fig.1. Block diagram of a slave system with direct additive shape model errors for robust synthesis and analysis.

By isolating the corrector $\mathrm{K}$ to determine the matrix of the open-loop interconnection $\mathrm{P}$ and the closed-loop transfer matrix M, FIG. 2 below:

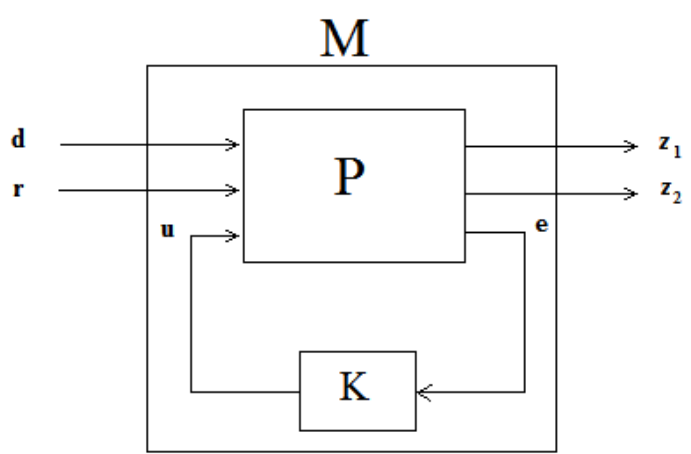

Fig.2. Block diagram for the distinction between matrix $\mathrm{M}$ and matrix $\mathrm{P}$. Considering all these hypotheses, we obtain as corrector in longitudinal and lateral flight by synthesis :

$\|H\|_{\infty}$ :

$$
K_{l o}=\left[\begin{array}{c}
1,09410^{-4} \mathrm{~s}^{3}-1.16310^{5} \mathrm{~s}^{2} \\
+3.63710^{7} \mathrm{~s}+6.01210^{7} \\
\hline \mathrm{s}^{3}+8.80410^{8} \mathrm{~s}^{2}+ \\
3.4710^{11} \mathrm{~s}+4.2210^{10} \\
-4.88810^{-5} \mathrm{~s}^{3}-3.6410^{4} \mathrm{~s}^{2} \\
\frac{-8.12210^{6} \mathrm{~s}-1.99810^{7}}{\mathrm{~s}^{3}+8.80410^{8} \mathrm{~s}^{2}+} \\
3.4710^{11} \mathrm{~s}+4.2210^{10} \\
1.1510^{-5} \mathrm{~s}^{3}+7810 \mathrm{~s}^{2} \\
\frac{1.49810^{6} \mathrm{~s}+1.20610^{7}}{\mathrm{~s}^{3}+8.80410^{8} \mathrm{~s}^{2}+} \\
3.4710^{11} \mathrm{~s}+4.2210^{10} \\
-1.05110^{-5} \mathrm{~s}^{3}-8552 \mathrm{~s}^{2} \\
\frac{-1.63610^{6} \mathrm{~s}+3.31910^{7}}{\mathrm{~s}^{3}+8.80410^{8} \mathrm{~s}^{2}+} \\
3.4710^{11} \mathrm{~s}+4.2210^{10}
\end{array}\right.
$$

$$
\begin{gathered}
-0.353 \mathrm{~s}^{3}-3.90610^{9} \mathrm{~s}^{2} \\
-7.56910^{11} \mathrm{~s}-7.81910^{9} \\
\hline \mathrm{s}^{3}+8.80410^{8} \mathrm{~s}^{2}+ \\
3.4710^{11} \mathrm{~s}+4.2210^{10} \\
0.1577 \mathrm{~s}^{3}+2.50910^{8} \mathrm{~s}^{2} \\
+1.58610^{11} \mathrm{~s}-9.41310^{9} \\
\hline \mathrm{s}^{3}+8.80410^{8} \mathrm{~s}^{2}+ \\
3.4710^{11} \mathrm{~s}+4.2210^{10} \\
-0.03708 \mathrm{~s}^{3}-7.17210^{7} \mathrm{~s}^{2} \\
-4.35710^{10} \mathrm{~s}+1.26510^{10} \\
\hline \mathrm{s}^{3}+8.80410^{8} \mathrm{~s}^{2}+ \\
3.4710^{11} \mathrm{~s}+4.2210^{10} \\
0.0339 \mathrm{~s}^{3}+4.16810^{7} \mathrm{~s}^{2}+ \\
3.22910^{10} \mathrm{~s}+5.4410^{10} \\
\hline \mathrm{s}^{3}+8.80410^{8} \mathrm{~s}^{2}+ \\
3.4710^{11} \mathrm{~s}+4.2210^{10}
\end{gathered}
$$

$$
K_{l a}=\left[\begin{array}{c}
1298 \mathrm{~s}^{2}+1.7710^{14} \mathrm{~s} \\
+1.83810^{\wedge} 14 \\
\hline \mathrm{s}^{3}+1.25510^{11} \mathrm{~s}^{2} \\
+4.52610^{14} \mathrm{~s}+6.0210^{14} \\
27.2 \mathrm{~s}^{2}+3.70910^{12} \mathrm{~s} \\
\frac{-2.15510^{12}}{\mathrm{~s}^{3}+1.25510^{11} \mathrm{~s}^{2}} \\
+4.52610^{14} \mathrm{~s}+6.0210^{14} \\
218.1 \mathrm{~s}^{2}+2.97410^{13} \mathrm{~s} \\
+2.11110^{13} \\
\hline \mathrm{s}^{3}+1.25510^{11} \mathrm{~s}^{2} \\
+4.52610^{14} \mathrm{~s}+6.0210^{14} \\
-361.2 \mathrm{~s}^{2}-4.92610^{13} \mathrm{~s} \\
-4.50210^{13} \\
\hline \mathrm{s}^{3}+1.25510^{11} \mathrm{~s}^{2} \\
+4.52610^{14} \mathrm{~s}+6.0210^{14}
\end{array}\right.
$$

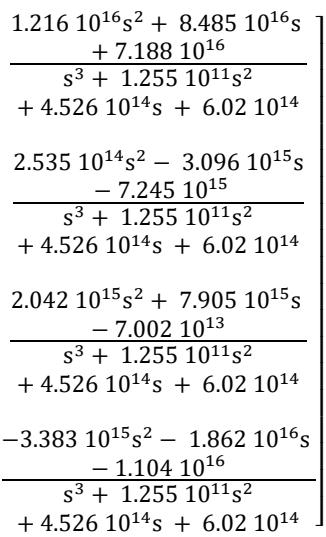

\section{SIMULATION DIAGRAM}

The helicopter is defined as consisting of several subsystems including fuselage, main rotor, tail rotor, empennage, engine,... The figure below illustrates the helicopter flight simulation model diagram and these different subsystems.

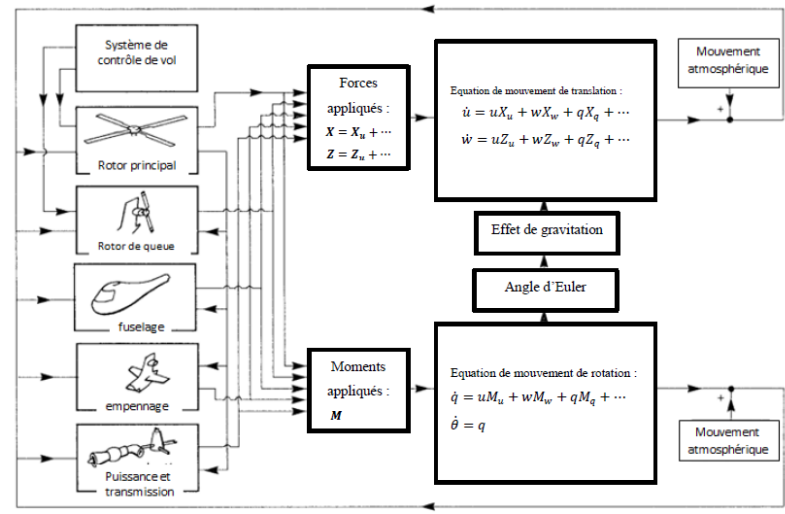

Fig.3. Simulation diagram of the longitudinal movement and these different subsystems.

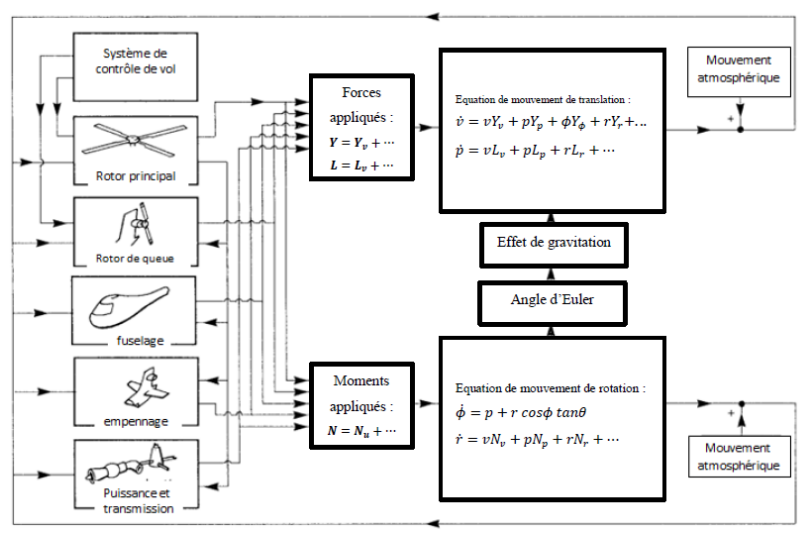

Fig.4. Simulation diagram of the lateral movement and these different subsystems.

3.3 State equation of the flight subsystem of the helicopter The equation of state of the longitudinal subsystem of the helicopter can be written in matrix form :

$$
\left[\begin{array}{c}
\dot{u} \\
\dot{w} \\
\dot{q} \\
\dot{\theta}
\end{array}\right]=\left[\begin{array}{cccc}
X_{u} & X_{w} & X_{q} & X_{\theta} \\
Z_{u} & Z_{w} & Z_{q} & Z_{\theta} \\
M_{u} & M_{w} & M_{q} & 0 \\
0 & 0 & 1 & 0
\end{array}\right]\left[\begin{array}{c}
u \\
w \\
q \\
\theta
\end{array}\right]+\left[\begin{array}{cc}
X_{\theta_{0}} & X_{\theta_{1 s}} \\
Z_{\theta_{0}} & Z_{\theta_{1 s}} \\
M_{\theta_{0}} & M_{\theta_{1 s}} \\
0 & 0
\end{array}\right]\left[\begin{array}{c}
\theta_{0}(t) \\
\theta_{1 s}(t)
\end{array}\right]
$$


With :

$A_{l o}=\left[\begin{array}{cccc}X_{u} & X_{w} & X_{q} & X_{\theta} \\ Z_{u} & Z_{w} & Z_{q} & Z_{\theta} \\ M_{u} & M_{w} & M_{q} & 0 \\ 0 & 0 & 1 & 0\end{array}\right] \quad B_{l o}=\left[\begin{array}{cc}X_{\theta_{0}} & X_{\theta_{1 s}} \\ Z_{\theta_{0}} & Z_{\theta_{1 s}} \\ M_{\theta_{0}} & M_{\theta_{1 s}} \\ 0 & 0\end{array}\right]$

$C_{l o}=\left[\begin{array}{llll}1 & 0 & 0 & 0 \\ 0 & 1 & 0 & 0 \\ 0 & 0 & 1 & 0 \\ 0 & 0 & 0 & 1\end{array}\right] \quad D_{l o}=\left[\begin{array}{ll}0 & 0 \\ 0 & 0 \\ 0 & 0 \\ 0 & 0\end{array}\right]$

One can write in matrix form the state equation of the lateral subsystem of the helicopter :

$A_{l a}=\left[\begin{array}{cccc}Y_{v} & Y_{p} & Y_{\phi} & Y_{r} \\ L_{v} & L_{p} & 0 & L_{r} \\ 0 & 1 & 0 & \cos \phi \tan \theta \\ N_{v} & N_{p} & 0 & N_{r}\end{array}\right] \quad B_{l a}=\left[\begin{array}{cc}Y_{\theta_{1 c}} & Y_{\theta_{0 T}} \\ L_{\theta_{1 c}} & L_{\theta_{0 T}} \\ 0 & 0 \\ N_{\theta_{1 c}} & N_{\theta_{0 T}}\end{array}\right]$

$C_{l a}=\left[\begin{array}{llll}1 & 0 & 0 & 0 \\ 0 & 1 & 0 & 0 \\ 0 & 0 & 1 & 0 \\ 0 & 0 & 0 & 1\end{array}\right] \quad D_{l a}=\left[\begin{array}{ll}0 & 0 \\ 0 & 0 \\ 0 & 0 \\ 0 & 0\end{array}\right]$

\section{RESULTS}

\subsection{Mu-analysis in longitudinal flight}

The frequency response of the lower and upper bounds of the structured and unstructured singular value of the matrix $M_{11}$, the nominal performance analysis matrix, for the corrector is shown in Fig 4.

\begin{tabular}{|c|c|c|}
\hline Looping & $\omega_{m}(\mathrm{rad} / \mathrm{s})$ & $\max \left[\mu\left(M_{11}\right)\right]$ \\
\hline$K_{l o}$ & $10^{3}$ & 0,2000 \\
\hline
\end{tabular}

Table.1 : Analysis of the nominal performance.

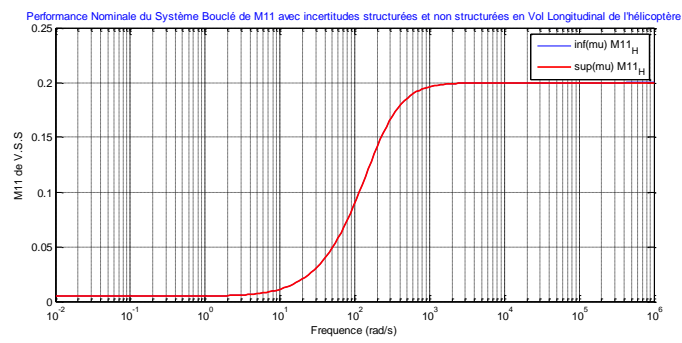

Fig.4. Nominal Performance of the Curly System.

The system is considered efficient because $\max \left[\mu\left(M_{11}\right)\right]<$ 1 for this loopback (Table 1).

The frequency response of the lower and upper bounds of the structured and unstructured singular value of the matrix $M_{22}$, stability stability analysis matrix, for the corrector is shown in FIG. 4.

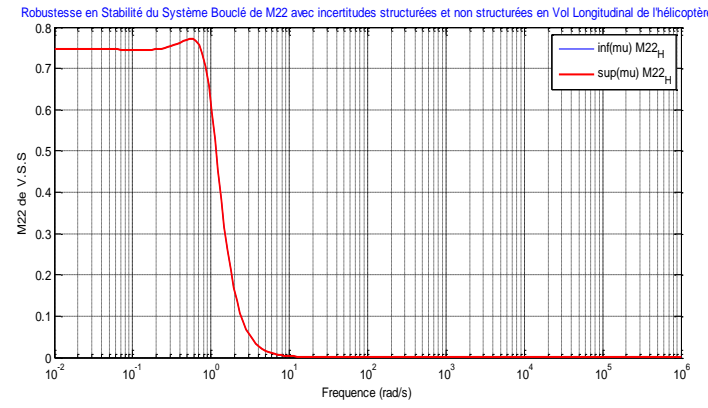

Fig.5. Robustness in Stability of the Curly System

\begin{tabular}{|c|c|c|c|}
\hline Looping & $\omega_{m}(\mathrm{rad} / \mathrm{s})$ & $\max \left[\mu\left(M_{11}\right)\right]$ & Stability guarantee \\
\hline$K_{l o}$ & 0,2341 & 0,7711 & $\|\Delta\|_{\infty}<\frac{1}{0,7711}$ \\
\hline
\end{tabular}

Table.2 : Analysis of robustness in stability.

The system is considered stable in robustness because $\max \left[\mu\left(M_{11}\right)\right]<1$ for this loopback.

The figure below shows the robustness in performance.

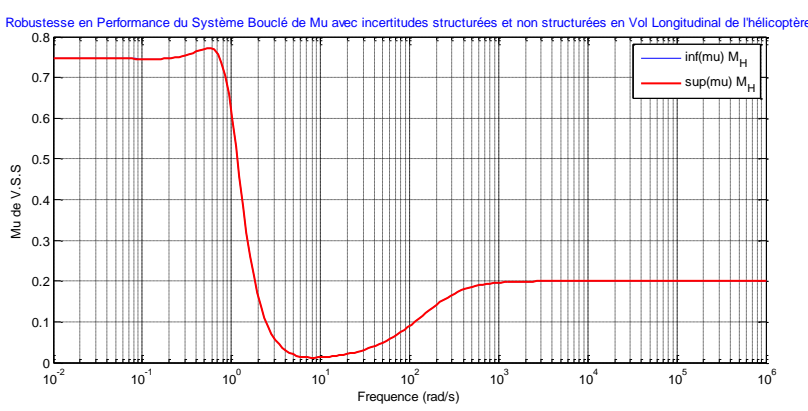

Fig.6. Robustness in Curly System Performance

The frequency response of the lower and upper bounds of the structured and unstructured singular value of the matrix $M$, the system for analyzing the robustness of the system, for each type of corrector is shown in Fig. 5.

\begin{tabular}{|c|c|c|c|}
\hline Looping & $\omega_{m}(\mathrm{rad} / \mathrm{s})$ & $\max [\mu(M)]$ & $\begin{array}{c}\text { Garantie de la } \\
\text { pérformance }\end{array}$ \\
\hline$K_{l o}$ & 0,2341 & 0,7725 & $\|\Delta\|_{\infty}<\frac{1}{0,7725}$ \\
\hline
\end{tabular}

Table.3 : Analysis of the robustness in performance.

The system is judged to be robust in performance because $\max [\mu(M)]<1$ for this loopback (Table 3). Yet there is a large guarantee of performance for looping with the corrector obtained by the synthesis $H_{\infty}$. 
4.2 Mu-analysis of systems in lateral flight

The block diagram for analyzing the system with unstructured uncertainties is shown in Fig. 6.

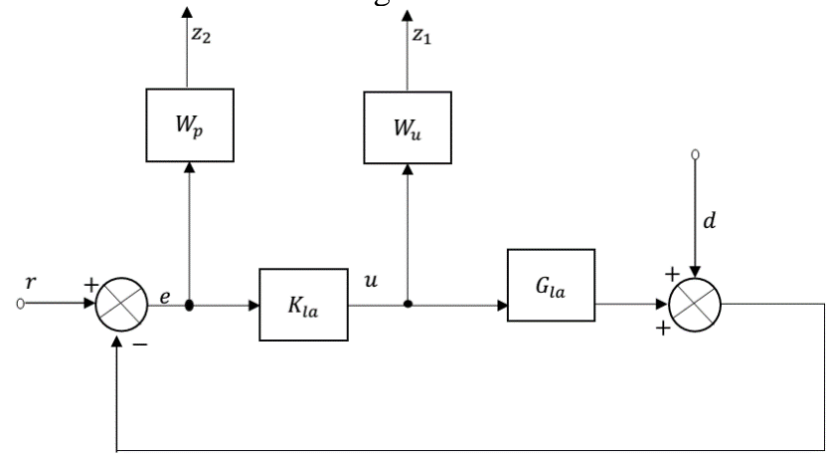

Fig.7. Block diagram of the disturbed system with unstructured uncertainties in lateral flight

The frequency response of the lower and upper bounds of the unstructured singular value of matrix $M_{11}$, the nominal performance analysis matrix, for the corrector is shown in the Fig. 8 below.

\begin{tabular}{|c|c|c|}
\hline Looping & $\omega_{m}(\mathrm{rad} / \mathrm{s})$ & $\max \left[\mu\left(M_{11}\right)\right]$ \\
\hline$K_{l a}$ & 0.7053 & 0,7741 \\
\hline
\end{tabular}

Table.4 : Analysis of the nominal performance.

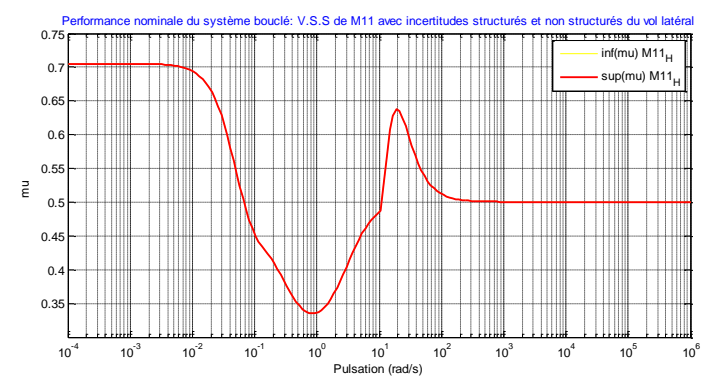

Fig.8. Nominal Performance of the Curly System

The system is considered efficient because $\max \left[\mu\left(M_{11}\right)\right]<$ 1 for this loopback.

The frequency response of the upper and lower bounds of the unstructured singular value of the matrix $M_{22}$, stability stability analysis matrix, for the corrector is shown in Fig. 9.

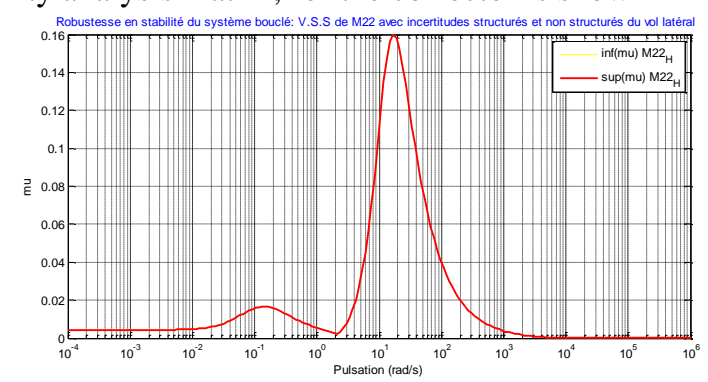

Fig.9. Robustness in Stability of the Curly System

\begin{tabular}{|c|c|c|c|}
\hline Looping & $\omega_{m}(\mathrm{rad} / \mathrm{s})$ & $\max \left[\mu\left(M_{11}\right)\right]$ & Stability guarantee \\
\hline$K_{l a}$ & $10^{5}$ & $6 \times 10^{(-7)}$ & $\|\Delta\|_{\infty}<\frac{1}{6 \times 10^{-7}}$ \\
\hline
\end{tabular}

Table.5 : Analysis of robustness in stability.
The system is considered stable in robustness because $\max \left[\mu\left(M_{11}\right)\right]<1$ for this loopback.

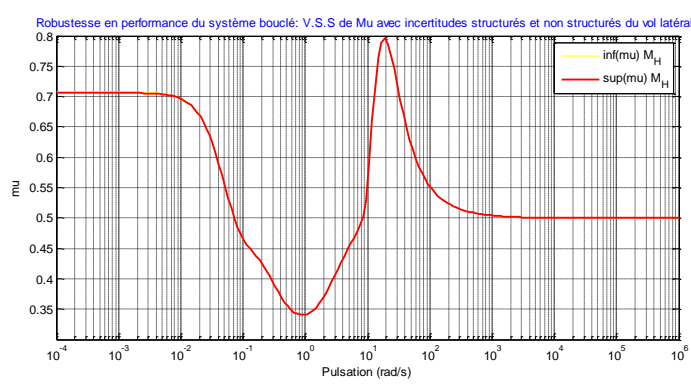

Fig.10. Robustness in Curly System Performance

The frequency response of the lower and upper bounds of the unstructured singular value of the matrix $M$, the system of analysis of the robustness of the system, for each type of corrector is shown in the figure below.

\begin{tabular}{|c|c|c|c|}
\hline Looping & $\omega_{m}(\mathrm{rad} / \mathrm{s})$ & $\max [\mu(M)]$ & Stability guarantee \\
\hline$K_{l a}$ & 0,5341 & 0,7741 & $\|\Delta\|_{\infty}<\frac{1}{0,7741}$ \\
\hline
\end{tabular}

Table.6 : Analysis of the robustness in performance.

The system is considered robust in robustness because $\max [\mu(M)]<1$ for this loopback. Yet there is a large guarantee of performance for looping with the corrector obtained by the synthesis $H_{\infty}$.

\section{CONCLUSION}

In this article, we have been able to develop robustness synthesis analysis tools for a linear system. Structured singular value is one of the very powerful tools for analyzing the robustness of a linear system tainted by uncertainty. It has been explained how the $\mu$-analysis method can analyze the robustness of stability and performance of a system. The standard problem explains the synthesis of a controller by minimizing the $\mathrm{H}$-infinite standard of the $\mathrm{LFT}_{l}(P, K)$. The resolution of this optimization leads to the determination of $\mathrm{K}$. The use of $\mu$-analysis and the problem of $\mathrm{H}$-infinity has established another synthesis tool that is $\mu$-synthesis.

\section{REFERENCES}

[1] G.M. Voorsluisjs, «Parameter dependent robust control for a rotorcraft UAV », Delft University of technology, 2629 HS Delft, The Netherlands, European conference for aerospace sciences, 2005.

[2] J.C. Wilson, R.E. Mineck, "Wind Tunnel investigation of helicopter - Rotor wake effects on three helicopter fuselage model", NASA TM-X-3185, 1975.

[3] S. Bouabdallah, P. Murrieri, R. Siegwart, «Design and Control of an Indoor Micro Quadrator », Proceedings of the IEEE, International Conference on Robotics and automation, New Orleans, LA, April 2004.

[4] A.K. Cooke, E.W.H. Fitzpatrick, "Helicopter test and evaluation", Blackwell Science, Qinetik, 2002;

[5] Fletcher, J.W., "Identification of UH-60 stability derivative models in hover from flight test data, AHS”, May 1993. 
[6] Fletcher, J.W., "A model structure for identification of linear models of the UH-60 helicopter in hover and forward flight", NASA TM 110362,August 1995.

[7] A. Isidori, L. Marconi, A. Serrani, « Robust Autonomous Guidance », Springer, 2003.

[8] A. Isidori, L. Marconi, A. Serrani, « Robust nonlinear motion control of a helicopter », IEEE Trans. Automat. Control, Vol 8, pp 413- 426, Springer, 2003.

[9] T.J Koo, S. Sastry, « Output tracking control design of a helicopter model based on approximate linearization », the $37^{\text {th }}$ Conference on decision and Control, Florida, USA, Vol 4, pp 3636-3640. 